concentrations of estradiol. This may be a result of the high circulating levels of FSH and LH postnatally, which cause hyperstimulation of the ovaries. The withdrawal of placental steroids at birth probably results in activation of the hypothalamicpituitary-gonadal unit. In full-term newborn infants, low levels of sex steroids inhibit the hypothalamic-pituitary-gonadal unit as a result of high sensitivity in the negative feedback system (3). The negative feedback system may be too immature in preterm girls to respond to low levels of estradiol. The finding in the present study that preterm girls have a postpubertal type of response to iv injection of LHRH when first examined but have a normal prepubertal type of response some months later, suggests that normal maturation of the hypothalamic-pituitarygonadal system takes place in utero during late gestation in the presence of high levels of estrogen. The maturation process in preterm girls in the extrauterine environment occurs without the negative feedback of the placental steroids, resulting in high levels of gonadotrophins and as a consequence a tendency to develop "the ovarian hyperstimulation syndrome."

MPA inhibits release of gonadotrophins and thus prevents hyperstimulation of the ovaries. We do not recommend this treatment as a routine procedure in all cases of estradiol-producing ovarian cysts, but at the moment we see no alternative treatment in infants with very high estrogen evels $(\gg 2000 \mathrm{pmol} /$ liter).

Acknowledgments. The authors thank C. Ewald for taking the samples for determination of serum concentrations, L. Wide for analysing the blood samples, and B. Östmark for skillful laboratory assistance.

\section{REFERENCES}

1. Kenny FM, Angsusingha K, Stinson D, Hotchkiss J 1973 Unconjugated estrogens in the perinatal period. Pediatr Res 7:826-831

2. Tapanainen J, Koivisto M, Vihko R, Huhtaniemi I 1981 Enhanced activity of the pituitary-gonadal axis in premature infants. J Clin Endocrinol Metab $52: 235-238$

3. Grumbach MM, Kaplan SL 1974 Fetal pituitary hormones and the maturation of central nervous system regulation of the anterior pituitary function. In: Gluck L (ed) Modern Perinatal Medicine. Year Book Medical Publishers Chicago, pp 247-271

4. Dubowitz LMS, Dubowitz V, Goldberg C 1970 Clinical assessment of gestational age in the newborn infant. J Pediatr 77:1-10

5. Finnström O 1977 Studies on maturity in newborn infants. IX. Further observations on the use of external characteristics in estimating gestational age. Acta Paediatr Scand 66:601-604

6. Wide L, Nillius SJ, Gemzell C, Roos P 1973 Radio-immunosorbent assay of follicle stimulating hormone and luteinizing hormone in serum and urine from men and women. Acta Endocrinol [Suppl] (Copenh) 174:1-58

7. Hotchkiss J, Atkinsson LE, Knobil E 1971 Time course of serum estrogen and luteinizing hormone $(\mathrm{LH})$ concentrations during the menstrual cycle of the rhesus monkey. Endocrinology 89:177-183

8. Bergqvist C, Esscher T, Lindgren PG, Lundkvist K, Sedin G 1984 Cystic ovaries in a pre-term newborn infant. $Z$ Kinderchir 39:403-404

9. Sedin $G 1983$ Hochfrequente Ueberdruckbeatmung in der Neugeborenenintensivbehandlung. In: Pohlandt $F$ (ed) Pädiatrische Intensivmedizin, Vol V, INA 41. George Thieme Verlag, Stuttgart, pp 50-53

10. Clements JA, Reyes FI, Winter JSD, Faiman C 1976 Studies on human sexual development. III. Fetal pituitary and serum, and amniotic fluid concentrations of LH, CG, and FSH. J Clin Endocrinol Metab 42:9-19

11. Winter JDS, Hughes IA, Reyes FI, Faiman C 1976 Pituitary-gonadal relations in infancy: 2. Patterns of serum gonadal steroid concentrations in man from birth to two years of age. J Clin Endocrinol Metab 42:679-686

12. Polhemus DW 1953 Ovarian maturation and cyst formation in children Pediatrics 11:588-594

13. Bidlingmeier F, Versmold H, Knorr D 1974 Plasma estrogens in newborns and infants. In: Forest MG, Bertrand J (eds) Endocrinologie Sexualle de la Periode Perinatale. Editions INSERM, Paris, 32:299-314

\title{
Alterations in Gas Exchange Associated with Lobar Atelectasis in Young Piglets
}

\author{
GREGORY J. REDDING, THOMAS A. STANDAERT, AND WILLIAM E. TRUOG \\ Department of Pediatrics, University of Washington School of Medicine, Seattle, Washington 98195
}

\begin{abstract}
Lobar atelectasis is common among infants and children with obstructive lung diseases. However, the effect of lobar collapse in the presence of diffuse lung disease on gas exchange in the pediatric age group has not been described. We developed an infant model of lobar atelectasis using piglets and tested the hypothesis that diffuse alveolar hypoxia increases shunt fraction $\left(\dot{Q}_{\mathrm{s}} / \dot{\mathrm{Q}}_{\mathrm{T}}\right)$ associated with lobar atelectasis by redirecting pulmonary blood from the well-ventilated portion of the lung into the collapsed region. Shunt fraction was determined using the multiple inert gas elimination technique. The proportion of pulmonary blood flow perfusing the left lower lobe was measured with microspheres. $\dot{\mathrm{Q}}_{\mathrm{s}} / \dot{\mathrm{Q}}_{\mathrm{T}}$ increased significantly but by a variable amount to an average value $( \pm \mathrm{SD})$ of 5.9
\end{abstract}

Received November 8, 1984; accepted February 6, 1985.

Reprint requests Dr. Gregory J. Redding, Department of Pediatrics, RD-20, Division of Neonatal and Respiratory Diseases, University of Washington, Seattle, WA 98195 .

Supported by NIH Grant HL19187 and MCH Grant 00955. $\mathbf{\pm} .2 \%$ following lobar collapse. The percentage of cardiac output perfusing the left lower lobe fell by an average of $70 \pm 17 \%$ in response to lobar collapse. When animals were ventilated with $12 \%$ oxygen, shunt fraction increased to $18.7 \pm 7.1 \%$ and blood flow to the collapsed left lower lobe increased from $9 \pm 3$ to $22 \pm 3 \%$ of cardiac output. Lobar atelectasis in conditions where diffuse alveolar hypoxia is present may be associated with a significantly greater intrapulmonary shunt than lobar atelectasis in children with otherwise normal lungs. (Pediatr Res 19: 552556,1985 )

\section{Abbreviations}

Ppa, pulmonary artery pressure

$\mathrm{PvO}_{2}$, mixed venous oxygen tension

$\mathrm{CO}$, cardiac output

TPR, total pulmonary resistance 
Lobar atelectasis is common among infants and children with obstructive lung diseases such as cystic fibrosis, bronchiolitis, and bronchopulmonary dysplasia (1-4). However, the effect of lobar collapse in the presence of diffuse lung disease on gas exchange in the pediatric age group has not been described. Previous studies in adult dogs with atelectasis demonstrate that intrapulmonary shunt is minimized as a result of regional hypoxic pulmonary vasoconstriction and reduction in blood flow to the atelectatic region $(5,6)$. It is unclear to what extent this compensatory mechanism occurs in young animals. Furthermore, the lungs of dogs in previous reports were normal aside from the area of collapse. This is unlike children with diffuse airway diseases in which multiple regions of alveolar hypoxia exist in addition to the region of atelectasis (7). To approximate more closely the clinical situation, we developed an infant model of lobar atelectasis using piglets, a species whose pulmonary vessels constrict vigorously in response to hypoxia (8). We then tested the hypothesis that diffuse alveolar hypoxia increases shunt fraction $\left(\dot{\mathrm{Q}}_{\mathrm{s}} / \dot{\mathrm{Q}}_{\Upsilon}\right)$ associated with lobar atelectasis by redirecting pulmonary blood flow from the well-ventilated portion of the lung into the collapsed region.

\section{METHODS}

Animal preparation. Twenty-one piglets, $2.2-5.3 \mathrm{~kg}$ and $7-21$ days of age, were anesthesized (pentobarbital, $20 \mathrm{mg} / \mathrm{kg}$ iv), intubated, paralyzed (pancuronium $0.2 \mathrm{mg} / \mathrm{kg}$ iv every hour), heparinized, and ventilated using a volume ventilator which delivered a $12 \mathrm{ml} / \mathrm{kg}$ (of body weight) tidal volume at a rate which maintained $\mathrm{PACO}_{2}$ between $35-45 \mathrm{~mm} \mathrm{Hg}$. Additional pentobarbital ( $4 \mathrm{mg} / \mathrm{kg}$ iv) was administered hourly in conjunction with pancuronium to maintain anesthesia throughout the experiment. Animals were sighed with twice the tidal volume every $15 \mathrm{~min}$ to minimize spontaneous development of atelectasis.

A no. 5 French double-lumen balloon tipped thermodilution catheter was placed via an external jugular vein into the left branch of the main pulmonary artery under fluoroscopy for continuous measurement of pulmonary artery pressure, intermittent measurement of mean pulmonary capillary wedge pressure, inert gas concentrations, and $\mathrm{PvO}_{2}$. Catheters were placed in the superior vena cava for infusion of an inert gas solution (see below) and in the ascending aorta for continuous monitoring of systemic arterial pressure (Psa) and intermittent sampling of arterial blood for inert gas concentrations, blood gas tensions $\left(\mathrm{PAO}_{2}, \mathrm{PACO}_{2}\right)$, and pH measurements. Pressures were measured using Hewlett-Packard 1280 transducers. Blood gas tensions and pH measurements were determined using a Corning 168 blood gas analyzer. Core body temperature was measured continually with a Yellow-Springs rectal probe. Body temperature was maintained at $38 \pm 0.5^{\circ} \mathrm{C}$ with a heating lamp to approximate the body temperature of awake piglets (9). CO was measured by thermodilution technique using an Edwards model 9510-A cardiac output computer. The coefficient of variation for $\mathrm{CO}$ when three measurements are made under each experimental condition with this equipment is $7.7 \pm 3.3 \%$.

A metal tracheotomy tube and a no. 7 French balloon tipped catheter were inserted through a tracheal incision site. The catheter tip was placed $1.5 \mathrm{~cm}$ below the carina in the left lower lobe bronchus under fluoroscopy. A nonrebreathing valve (10) which was electrically coupled to the ventilator allowed exhaled gas to pass into a heated collecting chamber where it was intermittently sampled for inert gas concentrations. Tidal volume and minute ventilation were measured using a hot wire anemometer attached to one end of the collection chamber (11). TPR (TPR = Ppa/ $\mathrm{CO}$ ) was calculated to reflect pulmonary vascular resistance.

Inert gas methodology - shunt fraction determination. Shunt fraction was determined using the multiple inert gas elimination technique described by Wagner et al. (12) and modified by Hlastala and Robertson (13). Shunt fraction is determined with this technique by simultaneously measuring the amount of a highly insoluble inert gas in mixed venous and arterial blood and in mixed expired gas. The amount of sulfur hexafluoride that remains in the blood as it passes through the lungs reflects the amount of lung with no effective ventilation, ie, intrapulmonary shunt. In these studies, six inert gases (sulfur hexafluoride, ethane, cyclopropane, halothane, diethyl ether, and acetone) were dissolved in normal saline and infused at a rate of $5 \mathrm{ml} / \mathrm{kg} / \mathrm{h}$ for at least $30 \mathrm{~min}$ prior to each measurement. The concentration of inert gases in 4-ml samples of mixed venous and arterial blood as well as $25 \mathrm{ml}$ of mixed expired gas were measured using a gas chromotograph (Beckman 72-5) equipped with a flame ionization detector and an electron capture detector (Analog Technolgy, Inc., Pasadena, CA) (14). Retention and excretion ratios for each inert gas were derived according to the methods of Hlastala and Robertson (13). Shunt fraction was derived from the difference between the ideal retention and excretion curves in the region of $\dot{V}_{\mathrm{A}} / \dot{\mathrm{Q}}<0.0001$.

Measurements of the distribution of pulmonary blood flow. The proportion of pulmonary blood flow perfusing the left lower lobe was measured with the injection of $9-\mu$ microspheres (3M Company, St. Paul, MN) labeled with $\mathrm{Sn}^{113}$ or $\mathrm{Nb}^{95}$ into the right ventricle under different experimental conditions in six animals. One-milliliter volumes containing approximately $5 \times 10^{4}$ microspheres were infused to assure that more than 10,000 counts of radioactivity per sample of lung tissue from each lobe were measured using a Packard gamma scintillation counter (15). Measurements of the heart and kidneys from these animals following microsphere injections showed no evidence of radioactivity demonstrating that few microspheres passed through or by the lungs into the systemic circulation. Proportion of blood flow to the left lower lobe $\left(\dot{\mathrm{Q}}_{\mathrm{LLL}} / \dot{\mathrm{Q}}_{\mathrm{T}}\right)$ was calculated as the activity of the left lower lobe divided by the total activity from all of the lobes.

Experimental design. Instrumented animals with $\mathrm{PAO}_{2}$ values of $>70 \mathrm{~mm} \mathrm{Hg}$ while ventilated with room air were enrolled into either an experimental (atelectasis) group or a control group. Gas exchange and hemodynamic measurements were made in the nine animals in the experimental group under each of three conditions: 1) ventilation with room air prior to atelectasis; 2) ventilation with room air $30 \mathrm{~min}$ after atelectasis was created and, 3) ventilation with a $12 \% \mathrm{O}_{2} 88 \% \mathrm{~N}_{2}$ gas mixture $1 \mathrm{~h}$ after atelectasis was produced. Immediately prior to bronchial balloon inflation, the animals were ventilated with $100 \%$ oxygen for 10 min to facilitate the development of absorption atelectasis.

The same three measurements were made in a control group of nine piglets at similar times following instrumentation under the same experimental conditions except that the endobronchial balloon was left uninflated in the lobar bronchus throughout the experiment.

Documentation of lobar atelectasis. Each animal was sacrificed with intravenous pentobarbital and potassium chloride at the conclusion of the experiment. The lungs were excised with the inflated endobronchial balloon in place and visually inspected to determine the extent of atelectasis. Atelectasis was present exclusively in the left lower lobe in the experimental group of animals. The excised lungs were then manually reinflated to a pressure of $50 \mathrm{~cm}$ of water while the endobronchial balloon remained inflated. All nine lungs distended and in three cases ruptured without reexpansion in the collapsed lower lobe. In contrast, no evidence of atelectasis was noted on visual inspection of the excised lungs from control animals.

To assess the time course of absorption atelectasis, three additional animals were sacrificed 10 min after bronchial balloon inflation. The specific gravity of the liver and collapsed left lower lobe were compared in each of these three animals and in four of the nine piglets whose endobronchial balloons were inflated for $4 \mathrm{~h}$. The average specific gravity values of the piglets' livers and atelectatic lobes which had been collapsed for $10 \mathrm{~min}$ and for $4 \mathrm{~h}$ were similar $(1.047 \pm 0.058$ versus $1.054 \pm 0.076$ versus $1.074 \pm 0.094$, respectively) suggesting that complete lobar collapse in animals ventilated with $100 \%$ oxygen occurred within 10 min after endobronchial occlusion and persisted thereafter. 
Table 1. Hemodynamic blood gas and shunt fraction values in the experimental and control groups of piglets

\begin{tabular}{|c|c|c|c|c|c|c|c|c|c|c|c|}
\hline & $\begin{array}{c}\mathrm{Ppa} \\
(\mathrm{mm} \mathrm{Hg})\end{array}$ & $\begin{array}{c}\text { Systemic } \\
\text { arterial } \\
\text { pressure } \\
(\mathrm{mm} \mathrm{Hg})\end{array}$ & $\begin{array}{l}\text { Pulmonary } \\
\text { capillary } \\
\text { wedge } \\
\text { pressure* } \\
\text { (mm Hg) }\end{array}$ & $\begin{array}{c}\mathrm{CO} \\
\text { (liter/min) }\end{array}$ & $\begin{array}{c}\text { TPR } \\
\text { (mm Hg/ } \\
\text { liter/ } \\
\text { min) }\end{array}$ & $\begin{array}{c}\mathrm{PAO}_{2} \\
(\mathrm{~mm} \mathrm{Hg})\end{array}$ & $\begin{array}{c}\mathrm{PvO}_{2} \\
(\mathrm{~mm} \mathrm{Hg})\end{array}$ & $\begin{array}{c}\mathrm{PACO}_{2} \\
(\mathrm{~mm} \mathrm{Hg})\end{array}$ & $\mathrm{pH}$ & $\begin{array}{c}\dot{\mathrm{Q}}_{\mathrm{s}} / \mathrm{Q}_{\mathrm{T}} \\
(\%)\end{array}$ & $\begin{array}{l}\dot{\mathrm{Q}}_{\mathrm{LLL}} / \dot{\mathrm{Q}}_{\mathrm{T}}^{\dagger} \\
\quad(\%)\end{array}$ \\
\hline \multicolumn{12}{|c|}{$\begin{array}{l}\text { Experimental group } \\
(n=9)\end{array}$} \\
\hline Room air & $15 \pm 5$ & $92 \pm 12$ & $3 \pm 2$ & $0.87 \pm 0.19$ & $18 \pm 4$ & $88 \pm 7$ & $37 \pm 6$ & $37 \pm 4$ & $7.47 \pm 0.05$ & $1.2 \pm 1.5$ & $29 \pm 5$ \\
\hline $\begin{array}{l}\text { Room air } \\
\quad+\text { atelectasis }\end{array}$ & $19 \pm 6 \ddagger$ & $91 \pm 9$ & $4 \pm 2$ & $0.88 \pm 0.22$ & $23 \pm 5 \ddagger$ & $76 \pm 6 \ddagger$ & $36 \pm 6$ & $41 \pm 5$ & $7.45 \pm 0.05$ & $5.9 \pm 4.2 \ddagger$ & $9 \pm 3 \ddagger$ \\
\hline $\begin{array}{l}\text { Hypoxia } \\
\quad+\text { atelectasis }\end{array}$ & $29 \pm 8 \S$ & $103 \pm 17$ & $4 \pm 1$ & $0.96 \pm 0.30$ & $31 \pm 11 \S$ & $37 \pm 8 \S$ & $22 \pm 4 \S$ & $42 \pm 5$ & $7.44 \pm 0.07$ & $18.7 \pm 7.1 \S$ & $22 \pm 3$ \\
\hline \multicolumn{12}{|l|}{$\begin{array}{l}\text { Control group } \\
(n=9)\end{array}$} \\
\hline Room air & $14 \pm 6$ & $81 \pm 11$ & $6 \pm 1$ & $0.88 \pm 0.24$ & $18 \pm 7$ & $95 \pm 10$ & $33 \pm 3$ & $34 \pm 9$ & $7.48 \pm 0.07$ & $0.9 \pm 0.8$ & \\
\hline Room air & $15 \pm 4$ & $83 \pm 8$ & $6 \pm 1$ & $0.88 \pm 0.33$ & $19 \pm 10$ & $90 \pm 13$ & $30 \pm 5$ & $38 \pm 3$ & $7.42 \pm 0.07$ & $0.9 \pm 0.8$ & \\
\hline Hypoxia & $32 \pm 5 \ddagger$ & $97 \pm 15$ & $5 \pm 1$ & $1.05 \pm 0.30$ & $30 \pm 14 \ddagger$ & $29 \pm 5 \ddagger$ & $14 \pm 5 \ddagger$ & $40 \pm 3$ & $7.34 \pm 0.06 \ddagger$ & $3.0 \pm 2.1$ & \\
\hline
\end{tabular}

$* n=3$ in group 1 and $n=5$ in group 2 .

$\dagger n=6$ during room air and during room air + atelectasis; $n=5$ during hypoxia + atelectasis.

$¥$ Significantly different than values in room air without atelectasis, $p<0.05$.

$\S$ Significantly different than values in room air with and without atelectasis, $p<0.05$.

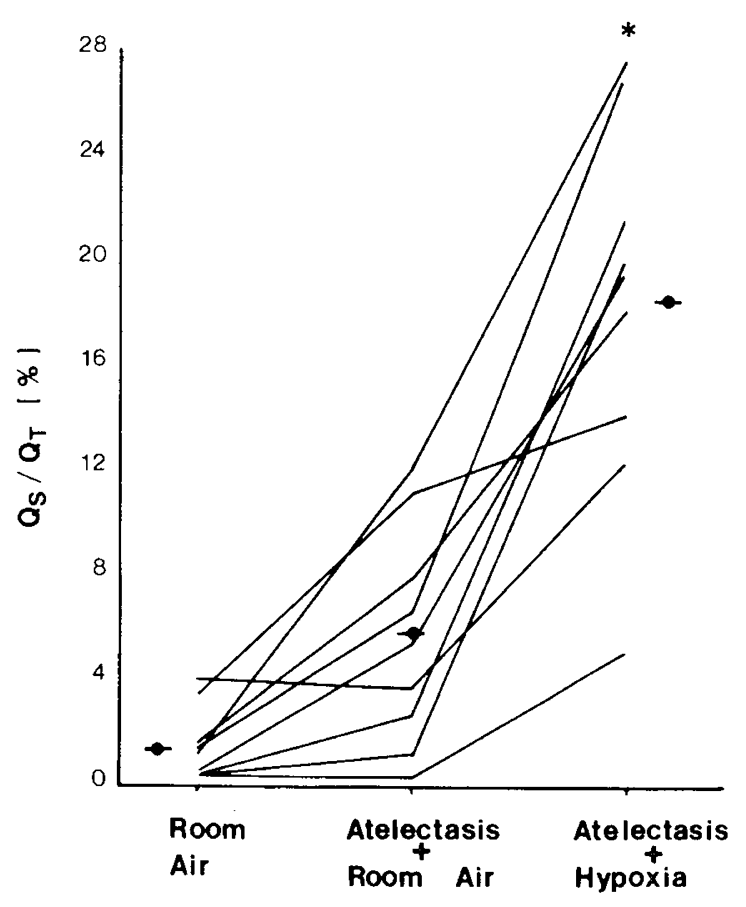

Fig. 1. Individual shunt fraction values in nine piglets ventilated with room air before and after developing lobar atelectasis and during ventilation with hypoxic gas following lobar collapse. - represents the mean value for the group under each experimental condition. ${ }^{*}$ indicates the projected shunt fraction during atelectasis had no regional hypoxic pulmonary vasoconstriction occurred (based on lobar blood flow measurements using radiolabeled microspheres).

\section{STATISTICS}

Hemodynamic, gas exchange, and blood flow distribution results measured under each experimental condition were compared statistically for both groups of piglets using a one-way analysis of variance and the Student-Newman-Keul test of multiple comparisons (16). Comparisons between the experimental and control groups of animals were made using the 2-tailed Student's $t$ tests. A $p$ value of $<0.05$ was considered significant.

\section{RESULTS}

Hemodynamic, blood gas, and $\dot{\mathrm{Q}}_{\mathrm{s}} / \dot{\mathrm{Q}}_{\mathrm{r}}$ values measured in the experimental and control groups during each experimental condition are presented in Table 1 . The results were identical for the two groups during normoxia prior to developing atelectasis. Blood flow to the left lower lobe prior to lobar collapse was 29 $\pm 5 \%$ of the total pulmonary blood flow in six piglets. After atelectasis was produced, Ppa and TPR increased $5 \pm 3$ and $5 \pm$ $2 \mathrm{~mm} \mathrm{Hg} / \mathrm{liter} / \mathrm{min}$, respectively, and $\mathrm{PAO}_{2}$ fell by $4 \pm 9 \mathrm{~mm} \mathrm{Hg}$ in the experimental group. These changes occurred in every animal with lobal collapse and were statistically significant. CO, pulmonary capillary wedge pressure, systemic arterial pressure, $\mathrm{PvO}_{2}, \mathrm{PACO}_{2}$, and $\mathrm{pH}$ were not influenced by lobar atelectasis during normoxia.

Individual shunt fractions for the experimental animals before and after atelectasis are illustrated in Figure 1. In every animal, $\dot{\mathrm{Q}}_{\mathrm{S}} / \dot{\mathrm{Q}}_{\mathrm{T}}$ increased significantly but by a variable amount to an average value $( \pm 1 \mathrm{SD})$ of $5.9 \pm 4.2 \%$ following lobar collapse. In all cases $\dot{\mathrm{Q}}_{\mathrm{S}} / \dot{\mathrm{Q}}_{\mathrm{T}}$ remained substantially below $29 \%$, the shunt that was predicted if the preatelectasis proportion of blood flow to the left lower lobes had persisted. In the six experimental animals studied with microspheres after atelectasis was created, $\dot{Q}_{s} / \dot{Q}_{t}$ was $7.3 \pm 5.5 \%$ and the percentage of $\mathrm{CO}$ perfusing the left lower lobe fell to $9 \pm 3 \%$ in response to lobar collapse (Table 1 ).

When the animals were ventilated with $12 \%$ oxygen, pulmonary artery pressure, and total pulmonary resistance increased and $\mathrm{PAO}_{2}$ and $\mathrm{PVO}_{2}$ fell significantly in both groups (Table 1). The control group experienced a lower $\mathrm{PvO}_{2}, \mathrm{pH}$, and $\dot{\mathrm{Q}}_{\mathrm{s}} / \dot{\mathrm{Q}}_{\mathrm{T}}$ than did the experimental group, but all other measurements were comparable between the groups. In the animals with atelectasis, the average shunt fraction increased to $18.7 \pm 7.1 \%$ when piglets with lobar atelectasis breathed $12 \%$ oxygen (Fig. 1). In five piglets with lobar collapse, blood flow to the collapsed left lower lobe increased from $9 \pm 3 \%$ of the $\mathrm{CO}$ in room air to 22 $\pm 3 \%$ during the hypoxic exposure (Table 1 ).

\section{DISCUSSION}

This study demonstrates that infant animals with lobar atelectasis effectively minimize intrapulmonary shunt by reducing pulmonary blood flow to the atelectatic region. The results are similar to those reported in normal adult dogs with lobar atelec- 


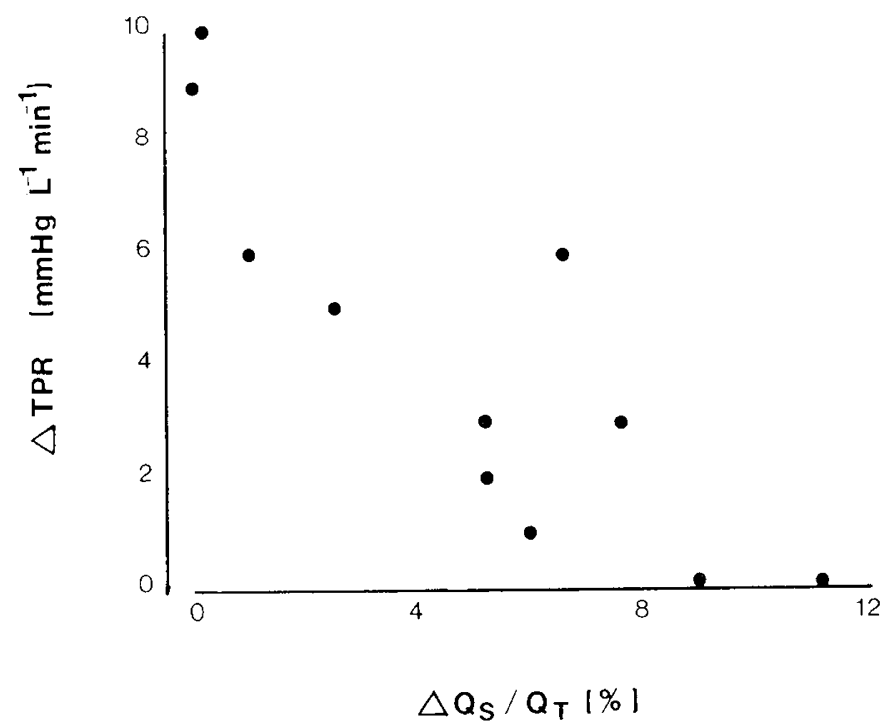

Fig. 2. The increase in shunt fraction correlates inversely with the increase in total pulmonary resistance following the development of lobar atelectasis in nine piglets ventilated with room air $(r=-0.85, p<$ 0.003 ).

tasis $(5,6)$. In these previous studies, regional hypoxic pulmonary vasoconstriction was found to be the primary mechanism responsible for minimizing gas exchange abnormalities associated with lobar atelectasis (6). The consistent rise in total pulmonary resistance in piglets following lobar collapse suggested that this mechanism of redistributing pulmonary blood flow is also operative in infant animals.

Piglets were used because of the morphometric similarities in their postnatal pulmonary vasculature compared to human infants (8). In both piglets and human newborns, medial smooth muscle surrounding the pulmonary arterioles is greater than that found in vessels of similar size among adults $(8,17)$. These findings suggest that pulmonary vessels can constrict more effectively in newborns compared to older animals and that shunt during lobar atelectasis might be more effectively minimized in infants compared to adults. In this report, the average shunt following lobar collapse was $5.9 \pm 4.2 \%$; among adult dogs left lower lobe atelectasis produced a $10-25 \%$ shunt fraction $(5,6)$. In piglets lobar blood flow was reduced to an average value of $9 \%$ of total pulmonary blood flow. Similar measurements in adult dogs revealed that $13-21 \%$ pulmonary blood flow perfused the atelectatic areas $(5,6)$. It is unclear whether these differences may reflect a species-related or an age-related difference in pulmonary vasoconstriction capabilities (18). It is clear, however, that normal newborn and infant animals are equally as capable as normal adults in minimizing intrapulmonary shunt associated with lobar collapse.

All piglets responded similarly to lobar atelectasis in a similar fashion but to a variable degree. The increase in pulmonary artery pressure and intrapulmonary shunt ranged from $2-9 \mathrm{~mm}$ $\mathrm{Hg}$ and $0-11 \%$, respectively. Previously, Thomas and Garrett (6) noted a similar variability among dogs with atelectasis and concluded that animals with more vigorous hypoxic pulmonary vasoconstriction more effectively redistributed pulmonary blood flow to well-ventilated regions of the lung, thereby minimizing shunt. We also found a strong negative correlation $(r=-0.85 p$ $<0.003$ ) between the increase in TPR and the increase in $\dot{Q}_{s} / \dot{Q}_{T}$ following lobar atelectasis in the nine piglets breathing room air (Fig. 2) thereby extending Thomas's observations to young animals of a different species.

When the piglets with lobar collapse experienced diffuse alveolar hypoxia, both pulmonary blood flow through the collapsed lobe and shunt fraction increased. These findings are consistent with those of Marshall and Marshall (19) who found that blood flow diversion away from a hypoxic region of lung toward normoxic regions diminishes as the hypoxic region increases in size. When piglets with lobar atelectasis were ventilated with $12 \%$ oxygen, the entire nonatelectatic region of lung became hypoxic. Pulmonary vascular resistance increased in the ventilated lung, rendering it less capable of receiving blood previously diverted from the collapsed lobe. As $\mathrm{CO}$ did not change under these conditions, blood flow to the atelectatic region increased and the elevated vascular resistance of the collapsed lobe diminished. The combined effect of increasing vascular resistance in the ventilated lung and decreasing vascular resistance in the collapsed lobe may explain why shunt fraction increased by an average of $165 \%$ while total pulmonary resistance increased by only $45 \%$.

We must speculate about the mechanisms which reduced hypoxic pulmonary vasoconstriction within the atelectatic lobe during diffuse alveolar hypoxia. Tucker et al. (20) found in dogs that doubling pulmonary blood flow to one lung attenuated its ability to constrict in response to hypoxia. Alveolar hypoxia in the ventilated lungs of the piglets may have forced blood to perfuse the atelectatic lobe, thereby distending and recruiting vessels in the collapsed region or rendering them less able to constrict. Alternatively, Sylvester et al. (21) found that alveolar oxygen tensions of less than $50 \mathrm{~mm} \mathrm{Hg}$ reduce the strength of hypoxic pulmonary vasoconstriction in isolated pig lungs. The fall in oxygen tension of mixed venous blood perfusing the piglets' atelectatic lobes from 36 to $22 \mathrm{~mm} \mathrm{Hg}$ with the addition of alveolar hypoxia could have produced a similar effect in our study. However, we found no correlation between $\mathrm{PvO}_{2}$ and shunt fraction in piglets with diffuse alveolar hypoxia and lobar collapse to confirm that such a phemonenon occurred.

We ventilated young piglets with lobar collapse with $12 \%$ oxygen in order to simulate diffuse alveolar hypoxia found among children with bronchiolitis, meconium aspiration syndrome, asthma, cystic fibrosis, and bronchopulmonary dysplasia. Lobar atelectasis occurs in $10-55 \%$ of children with these types of obstructive airway disease $(4,8,10,13)$. Our results indicate that lobar atelectasis in conditions where diffuse alveolar hypoxia is present may be associated with a significantly greater intrapulmonary shunt than lobar atelectasis in children with otherwise normal lungs. Conversely, the results suggest that supplemental oxygen may reduce intrapulmonary shunt despite persistent lobar collapse among such patients by reducing diffuse alveolar hypoxia and enhancing the distribution of pulmonary blood flow away from the atelectatic lobe.

\section{REFERENCES}

1. Gooding CA, Gregory GA 1971 Roentgenographic analysis of meconium aspiration of the newborn. Pediatr Radiol 100:131-135

2. James A, Brimblecombe FSW, Wells JS 1956 The natural history of pulmonary collapse in childhood. Q J Med 25:121-136

3. Moylan FMB, Shannon DC 1979 Preferential distribution of lobar emphysema and atelectasis in bronchopulmonary dysplasia. Pediatrics 63:130-134

4. Stern RC, Boat TF, Orenstein DM, Wood RE, Matthews, LW, Doershuk CF 1978 Treatment and prognosis of lobar and segmental atelectasis in cystic fibrosis. Am Rev Respir Dis 118:821-826

5. Metcalf JF, Wagner PD, West JB 1978 Effect of local bronchial obstruction on gas exchange in the dog. Am Rev Respir Dis 117:85-95

6. Thomas HM, Garrett RC 1982 Strength of hypoxic vasoconstriction determines shunt fraction in dogs with atelectasis. J Appl Physiol 53:44-51

7. Dantzker DR, Patten CA, Bower JS 1982 Gas exchange at rest and during exercise in adults with cystic fibrosis. Am Rev Respir Dis 125:400-405

8. Rendas A, Brauthwaite M, Reid L 1978 Growth of pulmonary circulation in normal pig-structural analysis and cardiopulmonary function. J Appl Physiol 451:806-817

9. Redding GJ, Tuck R, Escourreau P 1984 Nifedipine attenuates acute hypoxic pulmonary vasoconstriction in awake newborn piglets. Am Rev Respir Dis 129:785-789.

10. Truog WE, Standaert TA 1978 Non-breathing valve for spontaneously breathing or mechanically ventilated animals. J Appl Physiol 44:974-976

11. Godal A, Belenky DA, Standaert TA, Woodrum DE, Grumsrud L, Hodson WA 1976 Application of the hot-wire anemomenter to respiratory move- 
ments in small animals. J Appl Physiol 40:275-277

12. Wagner PD, Nauman PF. Lareruso RB 1974 Simultaneous measurement of eight foreign gases in blood by gas chromatography. J Appl Physiol 36:600605

13. Hlastala MP, Robertson HT 1978 Inert gas elimination characteristics of the normal and abnormal lung. J Appl Physiol 44:258-266

14. Copley DP, Klocke RA, Klocke FJ 1976 Quantitation of right to left shunt by double indication and oxygen techniques. J Appl Physiol 44:409-415

15. Hoffman JIE, Heymann MA, Rudolph AM, Payne BD 1977 Uses and abuses of the radioactive microsphere method of measuring regional blood flow. Bibl Anat 14:20-23

16. Zar JA 1974 Multiple comparisons. In: Biostatistical Analysis. Prentice-Hall Inc., Englewood Cliffs, NJ, pp 151-155
17. Haworth SG, Hislop AA 1981 Adaptation of the pulmonary circulation to extra uterine life in the pig and its relevance to the human infant. Cardiovasc Rev 15:108-119

18. Peake MD, Harabin AL, Brennan NJ, Sylvester JT 1981 Steady-state vascular responses to graded hypoxia in isolated lungs of five species. J Appl Physiol $51: 1214-1215$

19. Marshall BE, Marshall C 1980 Continuity of response to hypoxic pulmonary vasoconstriction. J Appl Phys 49:185-196

20. Tucker A, Reeves JT, Jackson DL, Grover RF 1978 Decreased pulmonary vascular responses in dogs with increased pulmonary blood flow. Can J Physiol Pharmacol 56:1011-1016

21. Sylvster JT, Harabin AL, Peake MD, Frank RS 1980 Vasodilator and constrictor responses to hypoxia in isolated pig lungs. J Appl Physiol 49:820-825

\title{
Effect of Bilirubin on Brainstem Auditory Evoked Potentials in the Asphyxiated Rat
}

\author{
JOHN H. JIRKA, R. BRADFORD DUCKROW, JAMES W. KENDIG, AND M. JEFFREY MAISELS \\ Division of Newborn Medicine, Department of Pediatrics, and the Division of Neurology, Department of Internal \\ Medicine, The Milton S. Hershey Medical Center, The Pennsylvania State University, College of Medicine, \\ Hershey, Pennsylvania 17033
}

\begin{abstract}
We measured brainstem auditory evoked responses (BAER) in four groups of paralyzed, ventilated, adult rats. Group $A(n=2)$ received intravenous albumin; group $B(n=5)$ received bilirubin in albumin; group $C(n$ $=7$ ) was asphyxiated and then received albumin; and group $\mathrm{D}(n=19)$ was asphyxiated and received bilirubin in albumin. When compared with control values, no changes in BAER occurred in groups A or B and only slight changes were found in group $C$. In group D, seven rats died and seven suffered a marked secondary deterioration of the BAER following recovery, a phenomenon that did not occur in group $C(p=0.02)$. Bilirubin toxicity appears to be responsible for the changes in BAER but prior asphyxia was necessary for this effect to occur. Because the changes that occurred in group D involved all four major waves, it is not possible to separate out a toxic effect of bilirubin, localized to the auditory nerve and the auditory pathway, from a generalized systemic effect which could cause attenuation of the entire response. The BAER may be useful, however, as a noninvasive means of identifying bilirubin toxicity in the newborn. (Pediatr Res 19: 556-560, 1985)
\end{abstract}

\section{Abbreviation}

BAER, brainstem auditory evoked response

BAER is the sound induced farfield reflection of electrical events generated within the auditory pathway in its progressive path through the brainstem (1-3). Because neurons of the cochlear nuclei and inferior collicular nuclei are sensitive to bilirubin

Received June 25, 1984; accepted February 6, 1985

Requests for reprints may be addressed to M. Jeffrey Maisels, M.D., Department of Pediatrics, The Milton S. Hershey Medical Center, Box 850, Hershey, PA 17033. injury $(4,5)$ and contribute to waveforms in the BAER, auditory evoked potentials might be useful in the detection of early bilirubin toxicity $(6-8)$.

In most animal species, hyperbilirubinemia alone fails to produce kernicterus. However, when hyperbilirubinemia is accompanied by an additional insult to the central nervous system (such as asphyxia), kernicterus may occur (9-11). We examined the effect of hyperbilirubinemia on the BAER in the adult rat, in the presence and absence of asphyxia.

\section{SUBJECTS AND METHODS}

Adult male Hooded Long-Evans rats, weighing 252 to $429 \mathrm{~g}$, were studied. Pentobarbital, $65 \mathrm{mg} / \mathrm{kg}$ body weight, was injected intraperitoneally for anesthesia. Blood gases and arterial blood pressure were measured via a femoral artery catheter. Intravenous injections of albumin or bilirubin in albumin were given via a catheter in the femoral vein. Temperatures were servocontrolled by means of a rectal probe and warming lamp. Tracheostomies were performed on all animals prior to mechanical ventilation with a Harvard Rodent Respirator no. 680. Tubocurarine, 2.5 to $3.0 \mathrm{mg} / \mathrm{kg}$ body weight, was injected intraperitoneally to minimize movement artifact on the evoked potential recording and arterial blood gases were maintained at established norms (12).

Far-field short-latency brainstem potentials were recorded from a vertex active needle electrode and a jaw needle electrode and amplified with a Grass P511J EEG amplifier bandpass filtered from 10 to $3000 \mathrm{~Hz}$. Click stimuli of $0.1 \mathrm{~ms}$ and $65.1 \mathrm{~dB}$ (SPL) were presented to the left ear at 10 clicks per second using a radio earphone (Radio Shack, no. 33-174) driven by $100 \mu \mathrm{S}$ square pulses of constant polarity. The radio earphone was calibrated with a Bruel and Kjaer (B \& K) type 2606 measuring amplifier coupled to a type 4152 artificial ear by means of a type 2627 preamplifier. AB \& K type 4144 pressure microphone was used in the artificial ear. Epochs of $10 \mathrm{~ms}$ were digitized at 10 